\title{
Effect of contraceptive steroids on monoamine oxidase activity
}

\author{
JENNifER SOUTHGATE, G. G. S. COLlins, J. PRYSE-DAVIES, AND
} M. SANDLER

From the Bernhard Baron Memorial Research Laboratories and Institute of Obstetrics and Gynaecology, Queen Charlotte's Maternity Hospital, London

SYNOPSIS Cyclical variations in monoamine oxidase activity during the human menstrual cycle, specific to the endometrium and modified in women undergoing contraceptive steroid treatment, may reflect changes in hormonal environment. Treatment of rats with individual constituents of the contraceptive pill causes analogous changes: oestrogens inhibit and progestogens potentiate uterine monoamine oxidase activity.

The enzyme monoamine oxidase (EC 1.4.3.4), which is probably involved in the inactivation in vivo of catecholamines, 5-hydroxytryptamine, tyramine, and other biologically active monoamines, has been studied with increasing intensity during the last five years. It is widely distributed throughout the body, the highest concentrations being found in the parotid gland (Strömblad, 1959) and liver (Bhagvat, Blaschko, and Richter, 1939). Relatively few observations are available on the localization and function of this enzyme in the female genital tract although there has been speculation on the possible role of placental monoamine oxidase in the pathogenesis of toxaemia of pregnancy (for review, see Southgate and Sandler, 1968). The rat uterine enzyme is inhibited or potentiated by oestrogen or progesterone respectively (Collins, Pryse-Davies, Sandler, and Southgate, 1970a). It seems likely that the human endometrial enzyme is similarly affected by these constituents of the 'pill'; the evidence by which we have been led to such a conclusion is set out below.

\section{Changes in Endometrial Monoamine Oxidase Activity during the Menstrual Cycle}

It appears that marked variations in the histochemical staining patterns of human endometrial monoamine oxidase occur during the menstrual cycle (Cohen, Bitensky, Chayen, Cunningham, and Russell, 1964; Cohen, Bitensky, and Chayen, 1965). Enzyme activity is low and confined to a particulate fraction during the proliferative phase, whereas later the staining is not only more intense but diffuse; shortly before menstruation, the particles appear to rupture releasing the enzyme into the cell cytoplasm. Cohen and his coworkers suggested that the non-particulate enzyme might be unable to oxidise catecholamines and that the resulting accumulation of vasoactive amines caused spasm of the spiral arteries and the start of menstruation. As histochemical assessment of enzyme activity can at best be semiquantitative, an attempt was made to correlate histochemical and direct biochemical measurements of the activity of monoamine oxidase in tissue samples from human endometrium (Southgate, Grant, Pollard, Pryse-Davies, and Sandler, 1968).

In order to obtain relatively normal endometrial samples, biopsy specimens were examined from 17 women aged 24-40 years attending the central clinic of the Council for the Investigation of Fertility Control and from 13 others aged between 21 and 47 years attending Chelsea Hospital for Women for a variety of minor disorders. The menstrual cycles and endometrial morphology of all subjects was normal and none was on hormonal treatment at the time of curettage.

The method of Wurtman and Axelrod (1963b) was used for biochemical estimation of mono- 
amine oxidase activity. Endometrial homogenates were incubated with ${ }^{14} \mathrm{C}$-tryptamine and the radioactive metabolites extracted into acidified toluene. An aliquot of the extract was counted in a liquid scintillation spectrometer and enzyme activity expressed as counts per minute per milligram dry tissue weight. For histochemical estimations, tissue sections were incubated with tryptamine and nitro-blue tetrazolium (Glenner, Burtner, and Brown, 1957) and the site of monoamine oxidase activity was localized by the intensity of formazan production. There was good correlation between the two procedures. In the $\mathbf{3 0}$ human biopsies investigated, monoamine oxidase activity was low in the early non-secretory phase of the cycle but at about the 19th to 21st day, which corresponds with the beginning of the late secretory phase, there was a sudden increase in enzyme activity (Fig. 1). Because of irregularities in human menstrual pattern, endometrial morphology gave a closer correlation with monoamine oxidase activity than did the actual day of the cycle.

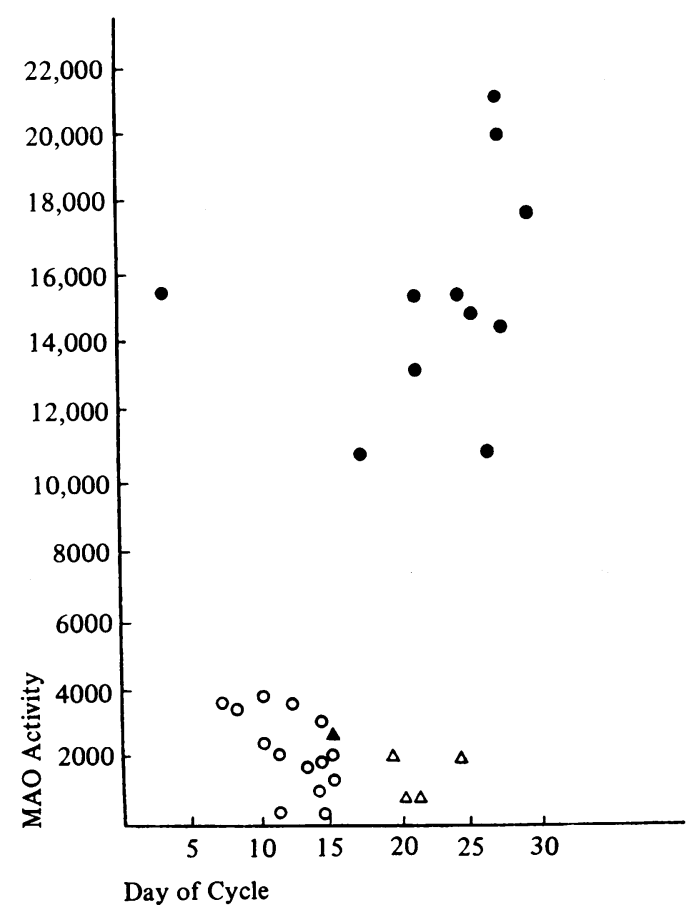

Fig. 1. The correlation of monoamine oxidase (MAO) activity with day of menstrual cycle and endometrial morphology. Enzyme activity is expressed as cpm/mg dry weight of tissue.

$\mathrm{O}=$ non-secretory

$\Delta=$ non-/early secretory

$\triangle=$ early secretory $\quad=$ late secretory

Reproduced from Biochem. Pharmacol., 17, 721

(1968), with permission of the Editor.
The intensity of staining of the endometria? glandular epithelium was used to assess mono? amine oxidase activity in human biopsiess (Southgate et al, 1968). Histochemical staining of sections from early and late secretory endomet:rium is shown in Figs. 2 and 3 respectively The scattered granular monoamine oxidase activity in the former is accompanied or replacef by a more diffuse blue coloration later in the cycle. These findings do not support the sug gestion of Cohen et al (1964) that the heavo diffuse staining represents an inactive form of the enzyme; indeed, the opposite would seem tọ be the case.

\section{Effect of Progestogens and Oestrogens on Human Endometrial Activity of Monoamine Oxidase}

Peak plasma progesterone levels occur at about the 20th day of the human menstrual cycle (Werth, 1955) and so it was thought that monoe amine oxidase activity might be progesterone dependent. In 1968, Grant and Pryse-Davie examined endometrial specimens from patients taking oral contraceptives; with the strongl罗 progestational type of 'pill', increased monoamine oxidase activity was detectable at the 12th day of the cycle whereas with strongls oestrogenic or sequential regimes, endometria enzyme activity was low throughout the cycleo These results provide added evidence that in the endometrium, monoamine oxidase activit $\vec{B}$ is in some way related to the hormonal environ 3 ment.

A unique case of a 35-year-old woman whơ at 23 weeks' gestation suffered from vaginat bleeding, for which she was given high dosage of hydroxyprogesterone and stilboestrol, pro3 vided additional evidence for the effect of hormones on monoamine oxidase activity? Despite treatment, she subsequently aborte at 26 weeks. In the foetus, weak but definite monoamine oxidase activity was detected i unusually vacuolated endometrial cells. In afother abortions and stillbirths which have beeţ examined, no endometrial monoamine oxidase activity was detectable before about 38 week of gestation. The foetal ovary was immature showing primordial but no Graafian follicles? and it would therefore appear unlikely thas enzyme activity was induced by the production of endogenous hormone.

\section{Platelet Monoamine Oxidase Activity during} the Menstrual Cycle

The question arose as to whether the cyclice changes in monoamine oxidase activity wer 


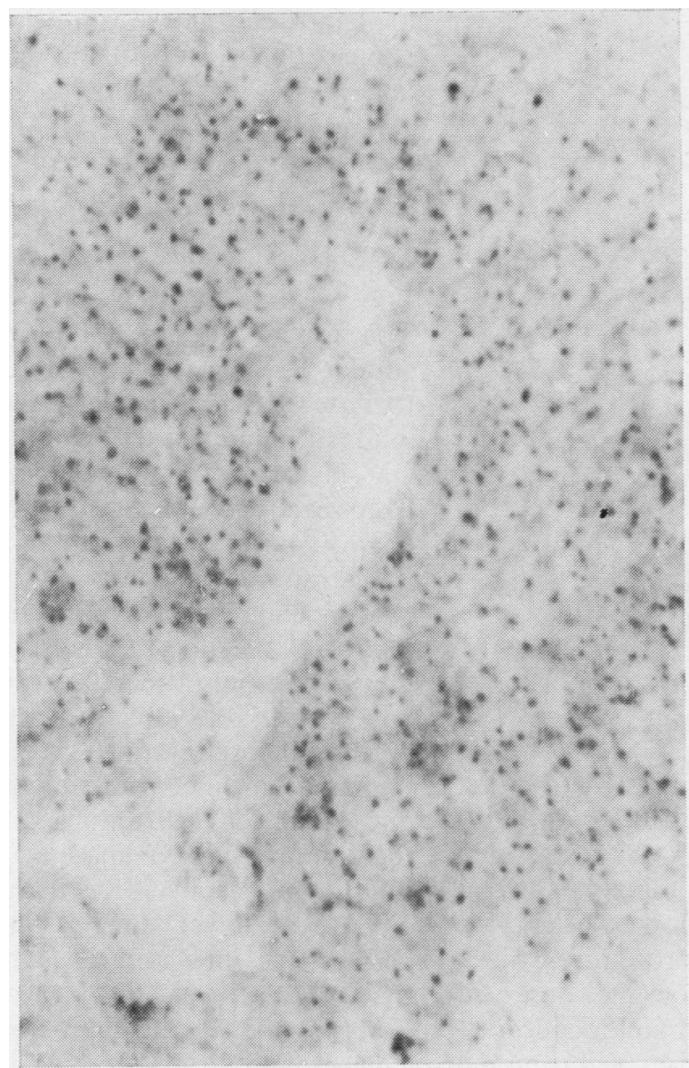

Fig. 2. Weak monoamine oxidase activity in proliferative endometrium on the eighth day of a normal cycle. The gland epithelium contains dark granular formazan particles and no diffuse stain. (Nitro blue tetrazolium method $\times 950$.)

peculiar to the endometrium. Blood platelet monoamine oxidase activity, a convenient index in vivo of the status of the enzyme (Paasonen, Solatunturi, and Kivalo, 1964; Latt, Rippey, and Stacey, 1968; Robinson, Lovenberg, Keiser, and Sjoerdsma, 1968), was therefore monitored in four women throughout the menstrual cycle.

Using plastic syringes, $4 \mathrm{ml}$ of venous blood was withdrawn weekly at the same time of day and was transferred to a plastic tube containing $5 \mathrm{mg}$ of ethylene-diamine tetra-acetic acid di-sodium salt (EDTA) and approximately $5 \mathrm{ml}$ of normal saline containing $2 \%(w / v)$ EDTA was added. After gently mixing and sedimenting red blood cells by centrifugation for $6 \mathrm{~min}$ at $500 \mathrm{~g}$ at room temperature, the supernatant was removed with a siliconized Pasteur pipette and spun at 2,000 $\mathrm{g}$ for $15 \mathrm{~min}$ at $4^{\circ} \mathrm{C}$. The platelet button was isolated and resuspended in $1.0 \mathrm{ml}$ of water. A $0.1 \mathrm{ml}$ aliquot of the suspension was assayed for monoamine oxidase activity using the spectrophotofluorimetric method described by Kraml (1965). Protein nitrogen was determined by the method of Lowry, Rosebrough, Farr, and Randall (1951) using

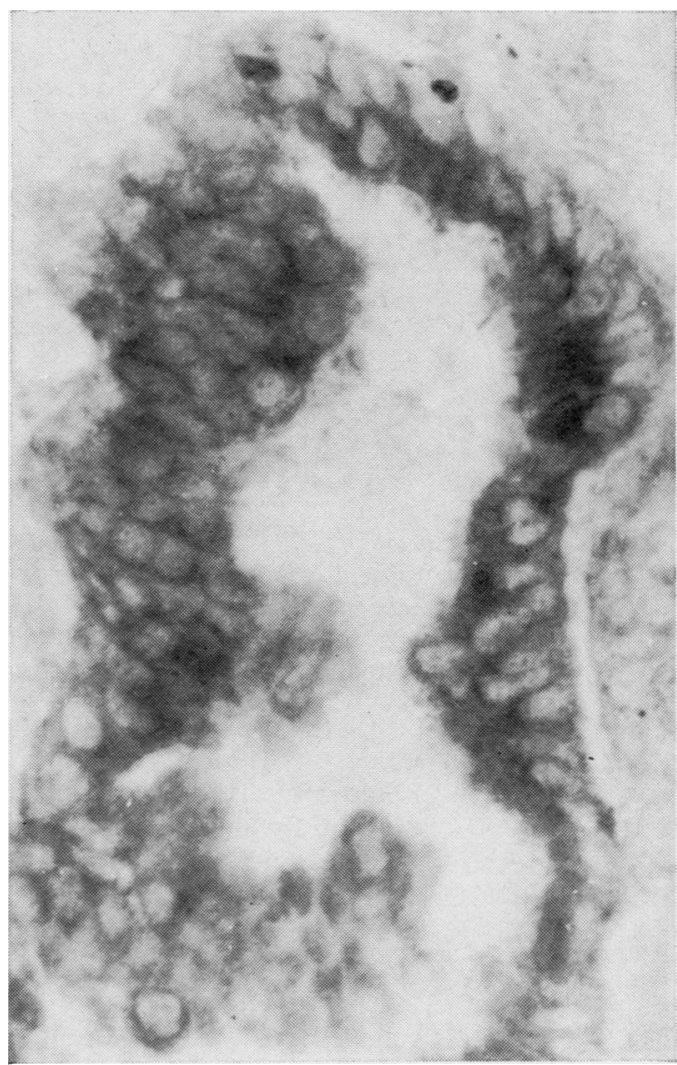

Fig. 3. Strong monoamine oxidase activity in late secretory endometrium on the 25th day of a normal cycle. The gland epithelium stains a diffuse dark blue colour. (Nitro blue tetrazolium method $\times 950$.)

crystalline bovine serum albumin as a standard. Towards the end of the cycle, monoamine oxidase activity appeared to fall (Fig. 4) but there was no rapid increase around the 19th to 21st days as had been found with the endometrial enzyme.

Klaiber, Kobayashi, and Broverman (1967) have reported that plasma tyramine oxidase activity (Kobayashi, 1966) fluctuates during the menstrual cycle reaching a peak on about the 24th day. Although this enzyme possesses certain similarities to the platelet enzyme, it is not established that it is a true monoamine oxidase (Levine, 1966).

\section{Rat Tissue Monoamine Oxidase Activity after Oestradiol and Progesterone Pretreatment}

Fluctuations in activity of monoamine oxidase during the oestrus cycle in various tissues of the rat have been reported (Kobayashi, Kobayashi, Kato, and Minaguchi, 1964; Kato and Minaguchi, 1964; Salseduc, Jofre, and Izquierdo, 1966; 


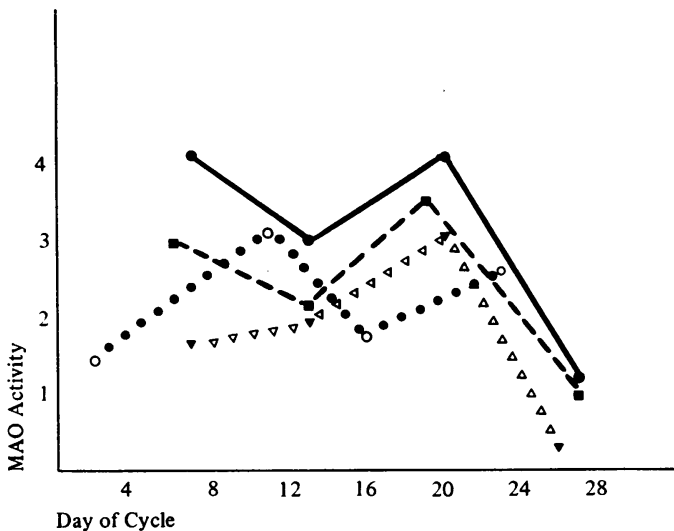

Fig. 4. Platelet monoamine oxidase activity during the menstrual cycle in four subjects. Enzyme activity is expressed as $\mu \mathrm{g}$ 4-hydroxyquinoline formed per 30 minutes' incubation per milligram protein.

7olovick. Pearse, Boehlke, and Eleftheriou, 1966; Cavanaugh and Zeller, 1967) and also in the guinea pig (Léonardelli, 1966) although Southgate et al (1968) were not able to detect any cyclical variations in rat endometrial enzyme using a histochemical assay procedure. Since the most likely explanation for the observed changes, as well as those in the human endometrium, must be based on alterations in hormonal environment, monoamine oxidase activity was measured in several rat tissues after pretreatment with oestradiol and progesterone (Collins, Pryse-Davies, Sandler, and Southgate, 1969a). Although these hormones may mediate the observed changes, it is equally possible that they only provide the trigger to initiate a chain of events culminating in the observed alterations in enzyme activity. There have been reports that tissue amine concentrations vary during the phases of the oestrus cycle (Rudzik arid Miller, 1962; Wurtman, Chu, and Axelrod, 1963). It is therefore possible that the cyclical changes in monoamine oxidase activity may be related to such changes in amine levels. In order to test this hypothesis, a further group of rats were pretreated with DL-DOPA (Collins et al, 1970a) to increase tissue concentrations of dopamine (Rosell, Sedvall, and Ullberg, 1963), a good substrate for monoamine oxidase (Weiner, 1960; Roth and Stjärne, 1966).

Twenty-four female white Wistar rats were divided into four groups of six animals. Two groups were injected subcutaneously on three consecutive days with $3.3 \mathrm{mg} / \mathrm{kg}$ progesterone and oestradiol respectively. A third group received 100 150,200 , and $300 \mathrm{mg} / \mathrm{kg}$ DL-DOPA intraperitoneally on four consecutive days whilst the fourth group was given saline injections. After treatment was completed, the animals were killed and tissue homogenates prepared from the ovaries, heart, brain, and liver which were subsequently fraction- ated into cell debris, mitochondria, and micrysomes (Hawkins, 1952). Monoamine oxidase activity was measured by the method described Kraml (1965).

After oestrogen pretreatment, there was significant fall in total monoamine oxidase activity of uterus and liver (Fig. 5). Progesteroge caused a significant increase in uterine actividy but was without effect on the other tissues. The administration of DL-DOPA resulted in $\mathbb{Q}_{a}$ similar specific increase in uterine monoamipe oxidase activity. These increases were evident in all subcellular fractions of the enzyme (Fig. $\odot$. On histochemical examination of four utemi from each group (Southgate et al, 1968), the changes after oestradiol and progesterone adiministration were found to correspond with the biochemical estimation; those after DEDOPA were less clear-cut. Apart from the uterus, the only other tissue in which drugs hod any measurable effect was the liver, in whief oestradiol pretreatment reduced activity. This finding is in line with similar data of Wurtman and Axelrod (1963a) and also correlates with the report of Cavanaugh and Zeller (196ฐ) that in mouse liver the activity of monoamime oxidase is lower during oestrus than in pre oestrus. It is probably relevant in this connexi@e that cardiac monoamine oxidase activity is lower in the female than the male rat (Skille日, Thienes, and Strain, 1962; Wurtman and Axelroe. 1963a). Oestrogen dosage gave rise to an uo equivocal decrease in rat uterine monoami oxidase and although this finding might not have been predicted from the data of earliẹr workers (Thompson and Tickner, 1949; Coveney,

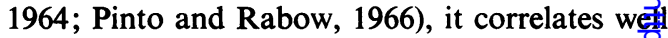
with our findings that its activity is lowest during the non-secretory phase of maximal oestroger secretion during the human menstrual cycte (Southgate et al, 1968). It has also recently beẹ reported that rat liver catechol-O-methyltrangferase, another enzyme which is involved in the inactivation of catecholamines (Axelrod, 1957, is competitively inhibited by 2-hydroxylated oestrogens but is unaffected by oestradiol (Knuppen, Lubrich, Haupt, Ammerlahn, and Breuer, 1969); the studies in vitro of Colli $x_{3}$ and Southgate (1969), on the other hand, showed that rat uterine monoamine oxidase is competite ively inhibited by $17-\beta$-oestradiol. Interpretatiog of these findings is still obscure. The situation is likely to be even more complex than appeass at first sight, for oestradiol exerts a regulatopy effect on progesterone metabolism in the femate rat liver (Wenzel, Langold, and Hallac, 1969).

It is not known whether amine concentratios in the human uterus vary during the menstruâ cycle although it has been established that the capacity of rat uterine tissue to bind adrenaline is more than four times greater during oestros than di-oestrus (Wurtman et al, 1963). The potentiation of monoamine oxidase activity in te 

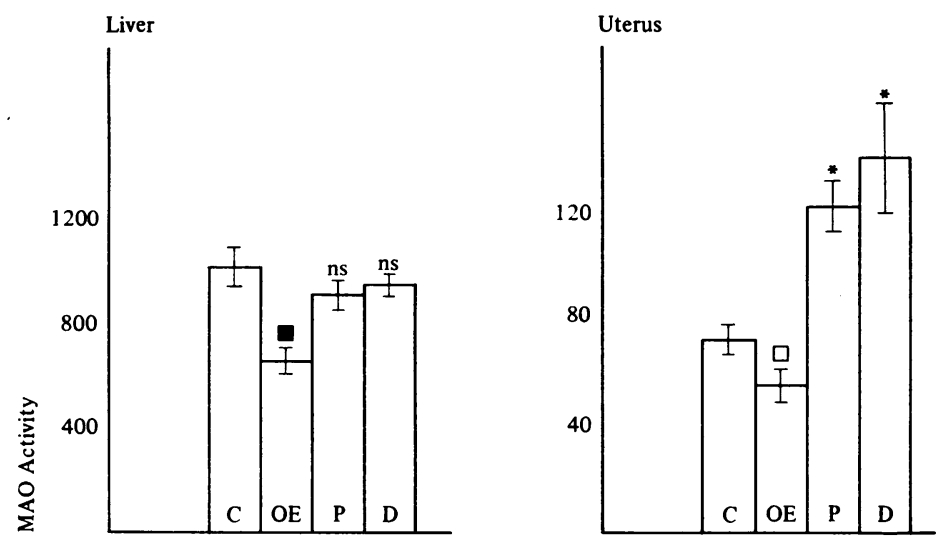

Fig. 5. Effect of oestradiol, progesterone, and $D L-D O P A$ on rat tissue monoamine oxidase. Enzyme activity expressed as nanograms kynuramine deaminated per minute of incubation per milligram protein $\pm S . E . C=$ control, $O E=$ oestrogen, $P=$ progesterone, $D=D L-D O P A$.

$\square<0.02 \square P<0.01 * P<0.001$. $N S=$ not significant.

Fig. 6. Effect of oestradiol, progesterone, and $D L-D O P A$ on tissue fractions of rat uterine monoamine oxidase.

Enzyme activity expressed as nanograms kynuramine deaminated per minute of incubation per milligram protein $\pm S E$. $C=$ control, $O E=$ oestrogen, $P=$ progesterone, $D=D L-D O P A$.

$\nabla P<0.05 \bigcirc P<0.005 * P<0.001$

Fig. 5 .

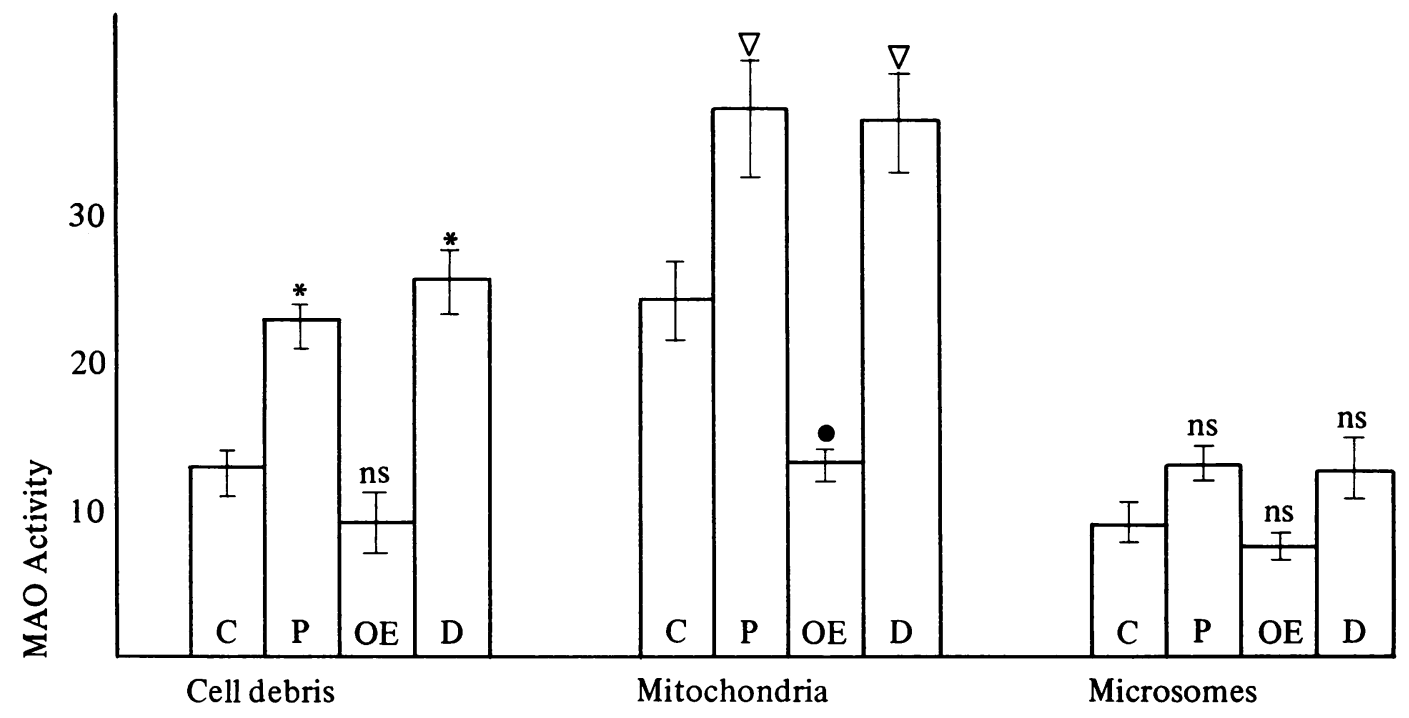

Fig. 6.

rat uterus by pretreatment with DL-DOPA suggests that variation in monoamine oxidase substrate concentrations may be involved in the control of enzyme activity; on the other hand, alterations in amine levels may be secondary to changes in monoamine oxidase. Whether the mechanism of action of the three drugs investigated is in any way interconnected or whether the pharmacological effects evoked possess any physiological counterpart cannot be decided on present evidence.

From the evidence presented it appears that rat uterine monoamine oxidase differs from that of the rat tissues in its sensitivity to oestradiol and progesterone. Evidence has accumulated that monoamine oxidase exists in multiple forms (Youdim and Sandler, 1967; Collins, Youdim, and Sandler, 1968; Youdim, Collins, and Sandler, 1969; Gomes, Igaue, Kloepfer, and Yasunobu, 1969; Collins and Youdim, 1969). For example, polyacrylamide gel electrophoresis of solubilized human brain monoamine oxidase separates four bands of activity (Collins, Youdim, Sandler, and Williams, 1970b) whereas human platelet monoamine oxidase consists of a single isoenzyme(Collins, 1969). Rat uterine monoamine oxidase has three bands of activity, one of which appears to be hormone sensitive (Collins and Southgate, 1969). This may provide an explanation for the changes in rat uterine monoamine oxidase activity after hormone pretreatment. If a similar situation is revealed in the human uterus, and the evidence summarized in this paper seems to make this likely, it is possible that the synthesis of a specific drug tailored to inhibit this band may eventually provide a quite novel approach to oral contraception. We are at present exploring this possibility.

\section{References}

Axelrod, J. (1957). O-Methylation of epinephrine and other catechols in vitro and in vivo. Science, 126, 400-401.

Bhagvat, K., Blaschko, H., and Richter, D. (1939). Amine oxidase. Biochem. J., 33, 1338-1341. 
Cavanaugh, M. J., and Zeller, E. A. (1967). Influence of sex hormones on succinate dehydrogenase (SUD) and monoamine oxidase (MAO) in various mice organs. Fed. Proc., 26, 814.

Cohen, S., Bitensky, L., and Chayen, J. (1965). The study of monoamine oxidase activity by histochemical procedures. Biochem. Pharmacol., 14, 223-226.

Cohen, S., Bitensky, L., Chayen, J., Cunningham, G. J., and Russell, J. K. (1964). Histochemical studies on human endometrium. Lancet, 2, 56-59.

Collins, G. G. S. (1970). In preparation.

Collins, G. G. S., Pryse-Davies, J., Sandler, M., and Southgate, J. (1970a). Effect of pretreatment with oestradiol, progesterone and DOPA on monoamine oxidase activity in the rat. Nature (Lond.), in the press.

Collins, G. G. S., Sandler, M., Williams, E. D., and Youdim, M. B. H. (1970b). Multiple forms of human brain mitochondrial monoamine oxidase. Nature (Lond.), in the press.

Collins, G. G. S., and Southgate, J. (1970), in preparation.

Collins, G. G. S., and Youdim, M. B. H. (1969). Further properties of multiple forms of mitochondrial monoamine oxidase. Biochem. J., 114, 80P.

Collins, G. G. S., Youdim, M. B. H., and Sandler, M. (1968). Isoenzymes of human and rat liver monoamine oxidase. FEBS Letters, 1, 215-218.

Coveney, J. (1964). Studies on monoamine oxidase and 5-hydroxytryptophan decarboxylase in mammallian tissues. Ph.D. thesis, University of London.

Glenner, G. C., Burtner, H. J., and Brown, G. W., (1957). The histochemical demonstration of monoamine oxidase activity by tetrazolium salts. J. Histochem. Cytochem., $5,591-599$.

Gomes, B., Igaue, I., Kloepfer, H. G., and Yasunobu, K. T. (1969). Amine oxidase. XIV. Isolation and characterisation of the multiple beef liver amine oxidase components. Arch. Biochem. Biophys., 132, 16-27.

Grant, E. C. G., and Pryse-Davies, J. (1968). Effect of oral contraceptives on depressive mood changes and on endometrial monoamine oxidase and phosphatases. Brit. med. J., 3 , 777-780.

Hawkins, J. (1952). The localisation of amine oxidase in the liver cell. Biochem. J., 50, 577-581.

Kato, J., and Minaguchi, H. (1964). Cholinergic and adrenergic mechanisms in the female rat hypothalamus with special reference to reproductive functions. Gunma Symposium on Endocrinology, 1, 269-281.

Klaiber, E. L., Kobayashi, Y., and Broverman, D. M. (1967) Plasma monoamine oxidase activity in ovulating and amenorrheic women. Abstr. 49th Meeting of the Endocrine Society, Miami Beach, Florida.

Knuppen, R., Lubrich, W., Haupt, O., Ammerlahn, U., and Breuer, H. (1969). Beeinflussung der enzymatischen Methlierung von Catecholaminen durch Ostrogene und vice versa. Hoppe-Seylers Z. physiol. Chem., 350, 1067-1075.

Kobayashi, Kobayashi, J., Kato, J., and Minaguchi, H. (1964). Fluctuations in monoamine oxidase activity in the hypothalamus of rat during the estrous cycle and after castration. Endocr. Japon., 11, 283-290.

Kobayashi, Y. (1966). The effect of three monoamine oxidase inhibitors on human plasma monoamine oxidase activity. Biochem. Pharmacol., 15, 1287-1294.

Kraml, M. (1965). A rapid microfluorimetric determination of monoamine oxidase. Biochem. Pharmacol., 14, 1684 1685.

Latt, N., Rippey, J. J., and Stacey, R. S. (1968). Monoamine oxidase activity of platelets. Brit. J. Pharmacol., 32, 427P.

Leonardelli, J. (1966). Ftude histoenzymologique de l'hypothalamus du Cobaye II. Detection de la monoaminoxydase chez le male et chez la femelle au cours du cycle oestral. C.R. Soc. Biol. (Paris), 160, 2072-2075.

Levine, R. J. (1966). Assessment of drug-induced inhibition of monoamine oxidase activity. Biochem. Pharmacol., 15, 1645-1647.

Lowry, O. H., Rosebrough, N. J., Farr, A. L., and Randall, R. J. (1951). Protein measurement with the Folin phenol reagent. J. biol. Chem., 193, 265-275.

Paasonen, M. K., Solatunturi, E., and Kivalo, E. (1964). Monoamine oxidase activity of blood platelets and their ability to store 5-hydroxytryptamine in some mental deficiencies. Psychopharmacologia, 6, 120-124.

Pinto, R. M., and Rabow, W. (1966). La acción del 17-B estradiol sobre la monoamino-oxidasa en placenta humana. Prensa Med., Argent., 53, 1151-1153.

Robinson, D. S., Lovenberg, W., Keiser, H., and Sjoerdsma, A. (1968). Effects of drugs on human blood platelet and plasma amine oxidase in vitro and in vivo. Biochem. Pharmacol., 17, 109-119.
Rosell, S., Sedvall, G., and Ullberg, S. (1963). Distribution an fate of dihydroxyphenylalanine-2-14C(DOPA) in mice. Biochem. Pharmacol., 12, 265-269.

Roth, R. H., and Stjärne, L. (1966). Monoamine oxidase activ in the bovine splenic nerve granule preparation. $A\left(\frac{\pi}{\pi^{2}}\right.$ physiol. scand., 68, 342-346.

Rudzik, A. D., and Miller, J. W. (1962). The effect of altering the catecholamine content of the uterus on the rate of contras tions and the sensitivity of the myometrium to relaxm. J. Pharmacol. exp. Ther., 138, 88-95.

Salseduc, M. M., Jofre, I. J., and Izquierdo, J. A. (1966). Mon amine-oxidase (E.C.1.4.3.4) and catechol-O-methyl tran ferase (E.C. 2.1.1a) activity in cerebral structures an sexual organs of rats during their sexual cycle. Mag. Pharmacol. exp., 14, 113-119.

Skillen, R. G., Thienes, G. H., and Strain, L. (1962). 5-Hydrox㛎 tryptamine, 5-hydroxytryptophan decarboxylase and monoamine oxidase in hearts of normal, thyroid-fed and propto thiouracil-fed male and female rats. Endocrinology, 70. 743-746.

Southgate, J., Grant, E. C. G., Pollard, W., Pryse-Davies, J., a Sandler, M. (1968). Cyclical variations in endometrial monoamine oxidase: correlation of histochemical af quantitative biochemical assays. Biochem. Pharmacol., th. 721-726.

Strömblad, B. C. R. (1959). Amine oxidase in human salivaćd glands. Lancet, 1, 1100 .

Thompson, R. H. S., and Tickner, A. (1949). Metabolism $\overrightarrow{\mathrm{if}}$ derivatives of $\beta$-phenylethylamine in pregnancy. Abs $(0)$ Ist int. Congr. Biochem., Cambridge, 429-430.

Weiner, N. (1960). Substrate specificity of brain amine oxidase $\frac{0}{\theta f}$ several mammals. Arch. Biochem. Biophys., 91, 182-188.-

Wenzel, M., Langold, M., and Hallac, P. (1969). Specific transter of hydrogen from oestradiol to progesterone as a regulatif principle for progesterone metabolism in the liver of tif female rat. J. biol. Chem., 244, 4523-4525.

Werth, G. (1955). Die gonadotropen Hormone. Arzneitis Forsch., 5, 735-746.

Wurtman, R. J., and Axelrod, J. (1963a). Sex steroids, cardi ${ }^{3} \mathrm{H}$-norepinephrine, and tissue monoamine oxidase leveb in the rat. Biochem. Pharmacol., 12, 1417-1419.

Wurtman, R. J., and Axelrod, J. (1963b). A sensitive and specif assay for the estimation of monoamine oxidase. Bioche Pharmacol., 12, 1439-1440.

Wurtman, R. J., Chu, E. W., and Axelrod, J. (1963). Relatio between the oestrous cycle and the binding of catechof mines in the rat uterus. Nature (Lond.), 198, 547-548.

Youdim, M. B. H., Collins, G. G. S., and Sandler, M. (1962) Multiple forms of rat brain monoamine oxidase. Natu (Lond.), 223, 626-628.

Youdim, M. B. H., and Sandler, M. (1967). Isoenzymes of solub3 monoamine oxidase from human placental and rat liver mitochondria. Biochem. J., 105, 43P.

Zolovick, A. J., Pearse, R., Boehlke, K. W., and Eleftheriou, B. (1966). Monoamine oxidase activity in various parts of the rat brain during the estrous cycle. Science, 154. 649. 